\title{
REFLEXÕES SOBRE A CULTURA JURÍDICA DESDE O PENSAMENTO DE RAYMOND WILLIAMS, JÜRGEN HABERMAS E PIERRE BOURDIEU.
}

\author{
Ivone Fernandes Morcilo Lixa ${ }^{1}$ \\ Carlos Eduardo do Nascimento ${ }^{2}$
}

Resumo: Considerando a cultura jurídica como conjunto de representações normativas elaboradas historicamente desde as relações de poder que expressa e legitima pensamentos hierarquicamente dominantes e elegendo a opção metodológica indutiva, o presente trabalho pretende, desde o pensamento de Raymond Williams acerca do conceito de cultura, de Jürgen Habermas sobre cultura jurídica e o de Pierre Bourdieu como possibilidade de aproximação entre ambos, discutir o direito e sua linguagem como expressão cultural que expressa significantes e significados que consolidam estruturas de dominação. Desde tal perspectiva, acredita-se ser possível visibilizar um horizonte crítico capaz de desvelar um fértil campo jurídico de reflexão.

Palavras chave: cultura; cultura jurídica; estruturas de dominação; racionalidade jurídica; poder simbólico.

\section{JURIDIC CULTURE REFLEXIONS ABOUT THE THOUGHT OF RAYMOND WILLIAMS, JÜRGEN HABERMAS AND PIERRE BOURDIEU.}

\begin{abstract}
Considering the juridic culture as a set of normative representations historically elaborated from the power relations that expresses and legitimizes hierarchically dominant thoughts and choosing the inductive methodological option, the present work intends, from Raymond Williams's thinking about the concept of culture, Jürgen Habermas's about legal culture and Pierre Bourdieu's as a possibility of approximation between both, discuss the law and its language as a cultural expression that expresses meanings productions and meanings itself that consolidate structures of domination. From this perspective, it is believed that it is possible to see a critical horizon capable of unveiling a fertile legal field for reflection.
\end{abstract}

Key words: culture; juridic culture; domination structures; juridic racionality; symbolic power.

\section{Introdução.}

A humanidade se desenvolve historicamente com uma consciência arcaica e simplória em relação à vida, atribuindo sua existência a uma mera perspectiva biológica em um

\footnotetext{
${ }^{1}$ Doutora em Direito pela Universidad Pablo de Olavide (Es) com pós doutoramento pela Universidade Federal de Santa Catarina (UFSC). Mestre em Direito pela Universidade Federal de Santa Catarina (UFSC). Professora, pesquisadora e extensionista do Curso de Direito da Universidade Regional de Blumenau Coordenadora do Programa de Mestrado em Direito da Universidade Regional de Blumenau (FURB/SC).

${ }^{2}$ Mestrando no Programa de pós-graduação em Direito na Universidade Regional de Blumenau (FURB), pósgraduando em Filosofia e Teoria do Direito pela PUC Minas, graduado em Direito na Universidade Regional de Blumenau (FURB), pesquisador do grupo CONSTINTER na Universidade Regional de Blumenau (FURB).
} 
constante conflito de uma explicação mitológica e, posteriormente, cosmológica do universo. Com o advento da modernidade, a mera existência biológica deixa de ser suficiente para as reivindicações humanitárias, havendo indagações e reflexões referentes à vida humana e consequentemente sobre suas necessidades. Assim, passa-se a compreender uma nova esfera que transpassa a mera subsistência humana, entendida como cultura.

Cultura é um termo de difícil conceituação, uma vez que sua invocação enquanto terminologia manifesta uma polissemia singular. Nas relações sociais, o termo é invocado de forma bastante vaga, variando desde um sinônimo de "arte" até uma outorga de adequação com princípios éticos de determinados grupos sociais. De forma geral, porém, deve-se entender que cultura invoca um sentido voltado à regionalidade, culminando em expressões instituídas nas tradições e costumes dos povos.

De acordo com Terry Eagleton (2003, p. 12) “a raiz latina da palavra «cultura»é colere, que pode significar tudo, desde cultivar e habitar até prestar culto e proteger”. Essa conceituação do pensador, por si só, demonstra que a variação polissêmica da palavra não apresenta uma averiguação simplória de diferenciação maniqueísta, atestando sua amplitude terminológica, mas, por sua vez, também não descreve um recorte teórico para que se possam desenvolver estudos através disso.

A necessidade de se desenvolver estudos e, concomitantemente, críticas às teorizações voltadas à perspectiva teórica do termo cultura está no descobrimento das estruturas de dominação e controle social que instrumentalizam as expressões culturais em detrimento de interesses individualizados e subjetivos. Nessa perspectiva, determinados grupos e classes passam a ser invisibilizados e excluídos das práticas sociais que estão atreladas às tradições dominantes.

Portanto, no sentido de problematizar e aprofundar o conceito de cultura jurídica o presente trabalho pretende, desde o pensamento de Raymond Williams acerca do conceito de cultura, o de Jürgen Habermas sobre cultura jurídica e o de Pierre Bourdieu como possibilidade de aproximação entre ambos, discutir o direito e sua linguagem como expressão cultural que expressa significantes e significados que consolidam estruturas de dominação.

\section{Cultura para Raymond Williams.}


Para Raymond Williams, a cultura se caracteriza por ser uma materialização sistemática dos significados construídos socialmente. Para o pensador marxista, que estuda o fenômeno através da metodologia materialismo-histórico dialético, a cultura é o "sistema de significações mediante o qual necessariamente [...] uma dada ordem social é comunicada, reproduzida, vivenciada e estudada" (WILLIAMS, 2011a, p. 13). Importante frisar que Williams buscou uma teoria materialista da cultura ${ }^{3}$ que levasse em conta seu papel social, tendo como meta tornar a história cultural em material. Isso se esclarece ao compreender que para Raymond Williams, a Cultura possui seu fim e verdadeira influência quando se molda de forma que se torne, posteriormente, material.

Analisando a construção do pensamento de Williams, entende-se que a Cultura se inicia e se desenvolve, inicialmente, em um processo semântico-histórico, ou semânticolinguístico. Isso se deve, pois as palavras possuem certas espécies de cargas de informação em que, em uma análise aprofundada, pode-se entender os significados, suas transformações e as estruturas de dominação inseridas nas próprias palavras. Isto demonstra que a ideia de "linguagem neutra" é uma falácia moderna, uma vez que produza sentidos, valores e significados - o que, por sua vez, compõe a legitimidade dos pensamentos hierarquicamente dominantes.

\footnotetext{
Quando percebemos de súbito que os conceitos mais básicos - os conceitos, como se diz, dos quais partimos - não são conceitos, mas problemas, e não problemas analíticos, mas movimentos históricos ainda não definidos, não há sentido em se dar ouvidos aos seus apelos. Resta-nos apenas, se o pudermos, recuperar a substância de que suas formas foram separadas. (WILLIAMS, 1979, p.17)
}

Um exemplo para demonstrar com maior clareza este fenômeno está na própria palavra cultura. Cultura inicia-se fazendo alusão à palavra "cultivo" - referindo-se à vida agropastoril e ao vínculo entre o homem e a terra - , renovando- se por volta do século XVIII, como referente à palavra "culto", como base civilizatória e intelectual. Porém, na versão

\footnotetext{
${ }^{3}$ Raymond Williams aproxima a categoria "material" da "simbólica" ao debater cultura como "sistema de significações", apontando que a expressão de uma atribui consequências à outra. Isso faz com que os termos inicialmente contrastantes se complementem. Ler mais em WILLIAMS, Raymond. Palavras-chave: um vocabulário de cultura e sociedade. Tradução de Sandra Guardini Vasconselos. São Paulo: Boitempo, 2007. P. 122.
} 
inglesa dominante até os anos 1960, cultura significava a grande tradição da literatura inglesa, remetendo à ideia de culto enquanto classe ou grupo intelectualmente superior.

Entendendo a variabilidade semântica do termo, o contexto de ressignificação da palavra e sentido de cultura, através de tradições e costumes, justifica-se, portanto, como "sistema de significações" reproduzido e comunicado a determinada ordem social. Nesse sentido, o material e o simbólico entram em fusão e passam a manifestar, dentro da sociedade, as artes, ciências e tecnologias (ou técnicas) como expressões de determinada cultura e determinado contexto.

A arte emana o sentido do subjetivo e indeterminado, que paira na esfera dos sentidos (sentimentos) e interpretação individual, como uma reprodução (representação) da vida e da realidade, mesmo não estando necessariamente a ela vinculada. Dentre suas manifestações, pode-se listar a literatura, a cinematografia, a pintura, a escultura etc.. Para Williams, a expressão artística, em especial a literária, é de suma importância para a compreensão do contexto cultural, uma vez que "a teoria literária não pode ser separada da teoria cultural, embora possa ser distinguida dentro dela" (WILLIAMS, 1979, p.145).

A ciência, por sua vez, caracteriza-se como manifestação racional e determinada, agindo por base de verificabilidade e controle, buscando e identificando limites e probabilidades do mundo essencialmente material, sempre com o anseio de superação. Ao se debater cultura jurídica, portanto, entende-se que o direito se expresse pela cultura, o que requer uma delimitação de sua expressão em algum campo. Nesse sentido, entende-se que o direito encontra-se materializado e expressado culturalmente pelo campo das ciências - por mais que isso não atribua um reducionismo jurídico à ideia estrita e formal de cientificidade tecnicista, como se verá adiante.

A técnica ou tecnologia, por fim, pode ser concebida como instrumento de manifestação das referidas expressões, agindo por meio de mediação instrumental transformadora e auxiliadora.

As expressões culturais se delineiam como campos que são condicionados e, ao mesmo tempo, condicionam o contexto cultural, o que legitima a dominação cultural de determinadas classes ou grupos, sendo que "em qualquer sociedade e em qualquer período específicos há um sistema central de práticas, significados e valores que podemos chamar apropriadamente de dominante e eficaz" (WILLIAMS, 2011b, p. 53). Williams passa a entender que a dominação se desenvolve através do procedimentos estéticos envoltos na 
cultura, pois a consciência social está intimamente ligada ao que sente, e o que sente está ligada às expressões estéticas - sendo as dominantes predominantes no cotidiano social.

Portanto, Williams irá justificar a perpetuação histórica de determinadas expressões dominantes como hegemônicas.

\begin{abstract}
A hegemonia supõe a existência de algo verdadeiramente total, não apenas secundário ou superestrutural, como no sentido fraco da ideologia, mas que é vivido em tal profundidade, que satura a sociedade a tal ponto e que [...] constitui mesmo a substância e o limite do senso comum para muitas pessoas sob sua influência, de maneira que corresponde à realidade da experiência social muito mais nitidamente do que qualquer noção derivada da fórmula de base e superestrutura. (WILLIAMS, 2011b, p. 51-52).
\end{abstract}

Assim, a hegemonia possui a vantagem de enfatizar a realidade da dominação (WILLIAMS, 2011b, 52). Não há de se confundir, portanto, hegemonia como "superestrutura", mas sim como "formações sociais reais", evidenciando, na concepção materialista de pensamento, como determinados grupos sociais impõem sua dominação cultural sobre outros periféricos - para Williams denominados subordinados - sendo que a dominação depende da legitimação pela sociedade, alcançada através da universalização dos significados e valores dominantes. É nesse ponto que uma classe dominante impõe - ou instaura - sua hegemonia na sociedade. Historicamente, esta hegemonia se perpetuará através daquilo que pode ser chamado de tradição ou costume. Em outras palavras, uma classe dominante adquire tal posição na sociedade ao controlar os meios de manifestação e expressão cultural, fazendo com que "certos significados e práticas são escolhidos e enfatizados, enquanto outros são negligenciados e excluídos” (WILLIAMS, 2011b, p. 54).

O processo de dominação da estética, porém, desenvolve algo que Williams chama de estrutura de sentimento, onde "procura articular a experiência intelectual e sua prática concreta" (PASSIANI, 2009, p. 286). Essa estrutura de sentimento está intimamente conectada à consciência social, que é condicionada pela contexto cultural em suas expressões estéticas. Portanto, quando certas convenções e instituições não mais conseguem expressar ou satisfazer aspectos importantes da vida, leva-se à criação de novas convenções, experimentações e formas estéticas, sendo nesses momentos que se despertam as consciências estéticas, onde pode-se perceber a dialética entre o que é "articulado" (significado) e o que é "vivido" (experiência/significante) (PASSIANI, 2009, p. 287). A consciência se manifesta na forma estética, sendo a experiência sempre social e materialista-histórica. 
A estrutura de sentimento é então uma resposta a mudanças determinadas na organização social, é a articulação do emergente, do que escapa à força acachapante da hegemonia, que certamente trabalha sobre o emergente nos processos de incorporação, através dos quais transforma muitas de suas articulações para manter a centralidade de sua dominação. (CEVASCO apud PASSIANI, 2009, p. 287).

Para o pensador, é através das estruturas de sentimento que a sociedade tem um despertar de consciência das estruturas hegemonizadas ao ponto de que se reconheçam as expressões culturais subalternas. Nesse sentido, Raymond Williams se atrela diretamente às questões estéticas historicamente estruturadas na sociedade, não havendo uma conexão direta com os estudos jurídicos, mas também não negando que essa materialidade das estruturas estéticas compõem um horizonte de significados que atingirão o direito tanto quanto as artes e os sistemas políticos e econômicos, uma vez que o direito também se consolida como expressão cultural.

\section{Direito como experiência histórica.}

Para entender o direito como uma experiência histórica, deve-se, antes, compreender qual o sentido emanado pela ideia de história que pretende-se trabalhar no presente ensaio. Neste sentido, considera-se a historia não como uma narrativa de acontecimentos, mas, sim, uma expressão de experiências coletivas humanas partilhadas e reproduzidas que definem determinadas mudanças estruturais nas relações sociais de poder, como uma trama da vida que move os sujeitos comuns desde seus desejos, necessidades, potencialidades, valores e interesses a criarem idealizações coletivas e rompendo com as estruturas e modelos dominantes.

Seguindo a conceituação, deve-se entender que o direito, desde essa perspectiva, assume uma natureza histórica. Isto porque as construções tradicionais e de costumes historicamente implantadas na sociedade contribuem para a formação de estruturas de ciência e de arte que se atrelem a estas construções. O direito, enquanto expressão interligada à um discurso racionalizado de acordo com os períodos históricos de lutas e emancipações, se atrela às diferentes perspectivas e contextos que o ungem à perspectiva racionalmente jurídica. Assim, considerando a historia como um processo de experiências de relações sociais 
acumuladas por um grupo social, sendo interiorizada e reproduzida, em uma relação de reciprocidade estruturalmente sistemática, o direito se expressa também como um fenômeno histórico, fazendo com que em si mesmo se acumulem tradições que se repetem, se interiorizam e se reproduzem como legítimas.

Essa experiência histórica que se alastra pelas tradições socialmente estruturadas onde o direito se materializa, é que se entende que a cultura, também condicionada a estruturas hegemonizadas pelas estruturas dominantes, expressa o direito como um resultado historicamente planejado de expressão de determinados contextos, conforme aludido no texto com Williams. Assim se consolida aquilo que chama-se "cultura jurídica", sendo a concepção de direito estruturada a partir de construções e expressões historicamente pautadas e materialmente consolidadas.

\section{Cultura jurídica para Habermas.}

Ao entender que o direito se expressa pela cultura, construindo o que podemos chamar de cultura jurídica, o processo hegemônico se materializa em sua expressão. Desta forma, o direito pode ser instrumentalizado assim como qualquer outra expressão cultural, para obedecer às requisições materiais e simbólicas das classes e grupos dominantes. Buscando uma solução dessa racionalidade instrumental (prática), uma faculdade subjetiva que corrobora com a perpetuação hegemônica do sistema jurídico desencantado com a sociedade e desalinhado com as reivindicações de grupos não dominantes, Habermas - um frankfurtiano de inclinações webberianas, alinhado indiretamente com a ideia de estrutura de sentimento que Williams trabalha - desenvolverá a teoria da racionalidade comunicativa.

Para Habermas, a razão comunicativa, situada em uma teoria reconstrutiva de sociedade, possibilita um alinhamento comunicativo para as tensões entre a facticidade e a validade das normas sociais através de um agir social que oferta uma mediação entre os diferentes sistemas e o mundo da vida. Essa perspectiva oferta uma superação do risco de dissenso. Por isso, "mediante a ação comunicativa, o potencial de racionalidade da linguagem é requerido, mobilizado e liberado no curso da evolução social para funções de integração social" (HABERMAS, 2020, p. 79).

A integração social, para Habermas, ocorre no âmbito da conexão dos sistemas (político, econômico e etc.) com o mundo da vida. Para o pensador, o mundo da vida possui 
uma especificação funcional de forma que "seus componentes - cultura, sociedade, estrutura de personalidade - se diferenciam precisamente nos limites de uma linguagem multifuncional, por cujo medium, porém, permanecem entrelaçados" (HABERMAS, 2020, p. 95).

Para o pensador, o medium dessas relações entre os sistemas e o mundo da vida seria o direito, podendo ser interpretado como cultura jurídica, que conserva uma função de charneira entre sistema e mundo da vida, ou seja, uma articulação entre os mundos que é incompatível com a representação de um isolamento e uma encapsulamento autopoiéticos do sistema jurídico, passando a funcionar como um transformador que assegura que a rede de comunicação socialmente integradora da sociedade em seu todo não se rompa (HABERMAS, 2020, p. 95-96). Por isso, corroborando com a ideia de condicionamento recíproco trazida por Williams, "cultura, sociedade e pessoa se pressupõem reciprocamente (HABERMAS, 2020, p. 125).

$\mathrm{Na}$ visão da teoria da ação comunicativa, podemos afirmar que o sistema de ação "direito", na qualidade de uma ordem legítima que se tornou reflexiva, pertence aos componentes sociais do mundo da vida. Da mesma maneira que este se reproduz junto com a cultura e as estruturas de personalidade pelo fluxo da ação comunicativa, também as ações jurídicas formam o medium através do qual as instituições jurídicas se reproduzem simultaneamente com as tradições jurídicas intersubjetivamente partilhadas e as capacidades subjetivas de interpretação e observação das regras jurídicas. Como parte dos componentes sociais, essas regras jurídicas formam ordens legítimas de nível superior, simultaneamente, porém, também são representadas nos outros dois componentes do mundo da vida enquanto simbolismo do direito e competências adquiridas pela socialização jurídica [...] Pertencem ao direito todas as comunicações que são orientadas ao direito, uma vez que as regras jurídicas se relacionam reflexivamente com a integração social realizada no processo de institucionalização . [...] a linguagem do direito, diferentemente da comunicação moral restrita às esferas do mundo da vida, funciona como um transformador entre sistema e mundo da vida, já que circula como parte da comunicação da sociedade em seu todo (HABERMAS, 2020, p. 125-126) (Grifo nosso). 
Ao entender, portanto, que o direito "pertence aos componentes do mundo da vida" e que se reproduz "junto com a cultura", Habermas soma conclusões aos estudos de Williams ${ }^{4}$. Mesmo que os pensadores sejam, a princípio, de linhas teóricas conflitantes entre si, Williams é cirúrgico ao entender o fenômeno da cultura como sistema de significações de dada ordem social (mundo da vida) e Habermas é riquíssimo em sua contribuição sobre o direito para os estudos culturais, elemento inobservado na teoria de Williams de forma direta.

Habermas ainda entende a dominação como podendo ser legal. Para o pensador, traduzindo o pensamento weberiano, A dominação legal não se refere apenas ao uso pouco claro do conceito de racionalidade, mas também ao tratamento do direito moderno nos limites de sua sociologia de dominação (HABERMAS, 2020, p. 115). Para o pensador, existem tipos de dominação APESAR do direito.

\begin{abstract}
Os tipos jurídicos servem a Weber em geral como fio condutor para a investigação dos tipos de dominação legítima; nisto, o direito moderno entra a tal ponto no nexo funcional com a dominação burocrática do instituto racional do Estado que a função de integração social própria ao direito não recebe mais a atenção devida. [...] o Estado de direito remete sua legitimação não à forma democrática da formação política da vontade, mas somente às premissas do exercício da dominação política da vontade em conformidade com o direito, a ser, à estrutura abstrata de regras das leis, à autonomia da jurisprudência tanto quanto à vinculação à lei e à construção "racional" da administração. [...] Em Weber resulta uma imagem especificamente alemã do Estado de direito à qual se incorpora a dominação elitista dos partidos políticos. (HABERMAS, 2020, p. 116).
\end{abstract}

O problema, portanto, reside nas afirmações anteriores no sentido da conversa entre os pensadores. Como pensadores de linhas teóricas "rivais" no ramo sociológico conversariam em uma análise sobre a cultura? Para isso, deve-se analisar ambas as obras de forma mais ampla, com uma teoria mais abrangente e híbrida.

\title{
5. Entre Williams e Habermas: o hibridismo teórico de Bourdieu.
}

\footnotetext{
${ }^{4}$ Essa ideia pode ser ainda mais fortalecida ao observar outra citação de Habermas, onde o autor diz que (2020, p. 125): "O mundo da vida se forma a partir de uma rede de ações comunicativas ramificadas em espaços sociais e tempos históricos; e as ações comunicativas não se alimentam somente das fontes de tradições culturais e ordens legítimas como dependem também das identidades de indivíduos socializados. [...] Os indivíduos socializados não conseguiriam se afirmar como sujeitos se não encontrassem apoio nas relações de reconhecimento recíproco, articuladas nas tradições culturais e estabilizadas em ordens legítimas - e vice-versa.”.
} 
Pierre Boudieu se destaca, assim como Jürgen Habermas e Raymond Williams, como um dos sociólogos mais importantes do século XX, quando passa a estudar as chamadas estruturas sociais. Para o pensador, a sociedade se molda através de certas estruturas estruturantes que se condicionam reciprocamente em uma constante construção social.

Dentre uma das maiores contribuições do pensador para a sociologia, está o seu rompimento com a sociologia hegemônica, onde Bourdieu nega a unidade teórica em apenas uma perna do tripé sociológico clássico e abraça o contexto todo, focando-se fortemente nas teorias de Karl Marx, com a leitura das classes sociais; em Durkheim, com a ideia de objetividade e; Max Weber com o subjetivismo e racionalismo instrumental.

O capital que estabelece essas classes teóricas não é apenas econômico, mas também social, cultural e simbólico. Ao se identificar tanto com Marx quanto com Weber, ou mais com Weber do que com Marx, a teoria de Bourdieu não se mostra inconsistente ou reacionária, mas, ao contrário, segue a tendência convergente que caracteriza abordagens mais recentes à teoria de classe. (SILVA apud TINEU, 2017, p. 104).

Ou seja, ao construir um hibridismo em suas inspirações sociológicas, Bourdieu traz tanto teorizações marxistas (luta de classes, estruturas de poder e etc.) quanto weberianas (razão instrumental, subjetivismo e etc). Porém, "Bourdieu, pelo viés weberiano, se torna mais weberiano que o próprio Weber ao incluir a dimensão cultural e simbólica na definição das chances de vida ou classe provável e não apenas na formação de grupos reais” (TINEU, 2017, p. 104).

O gosto legítimo, o gosto de nobreza ou a cultura legítima em Bourdieu se assemelham à dominação legítima de Weber por não haver a incidência ou necessidade do uso da violência como forma de dominação. O poder é reconhecido pela condição de classe social privilegiada (de nobreza ou aristocrática) tem em legitimar o gosto cultural, já o controle social ocorre também devido à tradição, ao carisma e à burocracia. (TINEU, 2017, p. 105).

O que há de se observar, porém, é que Williams, ao aproximar o material do simbólico, também corrobora com as teorias weberianas (cujo Habermas é adepto) de dominação sem o uso da violência física, se aproximando da ideia de dominação legítima de Weber e Bourdieu. 
Para as pretensões do presente trabalho, Bourdieu serve principalmente a este propósito, unir as teorias de Williams e Habermas em uma unidade científica a se desvelar posteriormente. Porém, a teoria de Bourdieu, por si mesma, já faz essa aproximação e, em determinados pontos, desenvolvimento, sozinha. Por isso, é imprescindível que se apresente a teoria de Bourdieu para que se compreenda tanto cultura quanto cultura jurídica nos tópicos levantados no presente trabalho.

\subsection{Pierre Bourdieu e o poder simbólico.}

Conforme aludido, Bourdieu desenvolve sua teoria através de uma ideia de estruturalismo crítico, onde a sociedade se edifica por estruturas estruturantes (bastante similar à ideia de condicionamento recíproco de Williams e também bastante próximo da sugestão de Habermas sobre o consenso social prévio para construção do direito e diminuição do risco de dissenso ${ }^{5}$ ). Essas estruturas estruturantes serão o campo de funcionamento do habitus.

O habitus, para Bourdieu, é uma espécie de interiorização dos hábitos cotidianos, seus valores e normas, sendo, com efeito, "princípio gerador de práticas objetivamente classificáveis e, ao mesmo tempo, sistema de classificação (principium divisionis) de tais práticas (BOURDIEU, 2011, p. 162). Os valores introduzidos na sociedade pelos sistemas e pela cultura são habitus, que além de uma estrutura estruturante que organiza as práticas e a percepção das práticas, é também estrutura estruturada, pois o princípio de divisão em classes lógicas que organiza a percepção do mundo social é, por sua vez, o produto da incorporação da divisão em classes sociais (BOURDIEU, 2011, p. 164).

Bourdieu entende que os habitus, ao serem instrumentalizados pelos grupos dotados de poder simbólico, criam capitais culturais (sociais, políticos e simbólicos). Esses capitais culturais acumulados geram dominação, e essa dominação gera violência simbólica (ou cultural).

\footnotetext{
${ }^{5}$ Para Habermas, existem dois tipos ideais para compor uma legalidade acordada de uma norma: (i) ser positivamente instituído e ser (ii) racionalmente acordado em conformidade com o direito válido de associação. Isso legitima a legalidade e facilita o consenso porque os sujeitos se submetem à coerção das regras sancionadas pelo Estado somente em virtude de um consenso fundamentado. (HABERMAS, 2020, p. 115). Em outras palavras, os sujeitos sociais entendem ao quê estão sujeitos porque tiveram participação na construção das normas coercitivas, o que faz com que a coercitividade seja racionalmente aceita.
} 
A dominação se estrutura através das citadas estruturas estruturantes, fazendo com que se solidifiquem em uma relação quase invisível para a sociedade. Essas solidificações (ou expressões) da dominação ocorrem de forma arbitrária e determinante, sendo impostas na sociedade por grupos dominantes e instituições de disposições incorporadas que criam habitus. Os habitus são reproduzidos na sociedade através das expressões culturais instrumentalizadas pelos grupos dominantes, o que se intensifica pelas expressões estéticas (conforme Williams). Perpetuados historicamente, os habitus que se consolidam hegemonicamente na sociedade se estruturam como tradições, solidificando as violências simbólicas.

Essas violências simbólicas são reproduzidas em espaços que reproduzem os discursos de dominação, como por exemplo as escolas. Essa violência é reproduzida em instituições por indivíduos que podem tentar persuadir outros com seus interesses. Essa persuasão é importante para a imposição da violência simbólica, pois "é uma violência que se exerce com a cumplicidade tácita daqueles que a sofrem e também, frequentemente, daqueles que a exercem na medida em que uns e outros são inconscientes de a exercer ou a sofrer" (BOURDIEU, 1997, p. 22). Para persuadir, instituições e grupos sociais usam títulos ou outras formas de proclamação de autoridade, conforme a instituição da dominação simbólica, podendo variar da estética (como aludido por Raymond Williams) até o direito (conforme aludido por Habermas ao falar da dominação burocrática e elitista). De forma mais direta, a violência simbólica é uma "[...] violência suave, insensível, invisível a suas próprias vítimas, que se exerce essencialmente pelas vias puramente simbólicas da comunicação e do conhecimento, ou, mais precisamente, do desconhecimento, do reconhecimento ou, em última instância, do sentimento" (BOURDIEU, 2003, p. 7-8).

Por entender que "o Estado é a posse do monopólio da violência física e simbólica" (BOURDIEU, 2014, p. 30), Bourdieu demonstra que o problema reside na dominação que instrumentaliza as expressões culturais que pairam no campo da atividade estatal. Sendo assim, a violência atinge todos as esferas do mundo da vida, mas se expressam desde o campo político e econômico até o campo jurídico.

Essas violências e desigualdades geradas pelas dominações simbólicas criam o que Bourdieu chamará de distinções, que, por sua vez, geram classificações sociais de acordo com os grupos dominantes e dominados. Bourdieu, portanto, enquanto contemporâneo da descolonização da Argélia, passa a ter consciência do papel social que as ciências 
desempenham, em especial a sociologia, alertando que o papel da sociologia é o de ser um esporte de combate, e não uma mera ciência analítica. Essa compreensão do pensador é importante, uma vez que se busque uma visão mais ampla dos fenômenos globais e, consequentemente, conceituações mais adequadas.

Seguindo esta perspectiva do pensador, pode-se compreender que os campos possuem uma lógica em que os dominados só podem encontrar no exterior, ou melhor, nos campos científicos e político, os princípios para uma argumentação crítica, sendo que esta crítica possibilitaria com que o direito, dentre outras expressões sociais, fosse transformado, visto e composto como ciência dotada de uma metodologia própria e firmada na realidade histórica (BOURDIEU, 1989, p. 252). Para Bourdieu, esta análise crítica da realidade histórica que toma corpo metodológico poderia ocorrer tecnicamente de diversas formas, mas a principal elencada pelo pensador é a jurisprudência.

Porém, as estruturas simbólicas, ao privilegiarem uma "intensificação da confrontação dos textos e dos procedimentos com as realidades sociais de que tais procedimentos são tidos por expressão e regulação" fomentam o "regresso às realidades que favorecem o aumento da diferenciação do campo e a intensificação da concorrência interna ao mesmo tempo que o reforço dos dominados no seio do campo jurídico" (BOURDIEU, 1989, p. 253).

Essa instrumentalização do campo jurídico por parte da estrutura simbólica que compõe a cultura e a sociedade, para Bourdieu, se dá por uma desconsideração que as visões internalista e externalista - antagonistas na proposta do autor - possuem em sua composição ideológica, que seria a da existência de um universo social relativamente independente em relação às pressões externas, no interior do qual se produz e se exerce a autoridade jurídica, forma por excelência da violência simbólica legítima cujo monopólio pertence ao Estado e que se pode combinar com o exercício da força física (BOURDIEU, 1989, p. 211).

Dessa forma, os juristas, enquanto autoridades legitimadas pelas estruturas do campo jurídico, passam a expressar, por sua mera existência, a violência simbólica dominante, mesmo que possam opor-se a respeito de textos cujo sentido nunca se impõe de maneira absolutamente imperativa em relação às problemáticas sociais, permanecendo, assim, inseridos em um corpo integrado de instâncias hierarquizadas que estão à altura de resolver os conflitos entre intérpretes a interpretações. Por esse motivo, as decisões judiciais só podem se distinguir de atos de força política enquanto se apresentarem como resultado necessário de uma interpretação regulada de suas "autoridades" a textos unanimemente reconhecidos, 
assemelhando-se a Justiça à Igreja e à Escola enquanto instituição proclamadora de poder e violência simbólica, uma vez que a Justiça “organiza segunda uma estrita hierarquia não só as instâncias judiciais e os seus poderes, portanto, as suas decisões e as interpretações em que elas se apoiam, mas também normas e as fontes que conferem a sua autoridade a essas decisões" (BOURDIEU, 1989, p. 214).

É válido, portanto, concluir que para Bourdieu, a cultura jurídica, ou o campo do direito que se expressa pela cultura simbólica composta pelas estruturas estruturantes dotadas de poder simbólico, instrumentaliza a si e a expressões oriundas de si, construindo uma estrutura de jurídica voltada ao poder de determinadas classes e categorias que se bonificam de interpretações interessadas na manutenção do poder simbólico existente e que acumula aquilo que o autor chamará de capital jurídico.

\footnotetext{
O antagonismo entre os detentores de espécies diferentes de capital jurídico, que investem interesses e visões de mundo muito diferentes no seu trabalho específico de interpretação, não exclui a complementariedade das funções e serve, de facto, de base a uma forma subtil de divisão do trabalho de dominação simbólica na qual os adversários, objectivamente cúmplices, se servem uns aos outros. (BOURDIEU, 1989, p. 219).
}

Bourdieu irá alertar para esta instrumentalização do campo do direito pelas estruturas de dominação simbólica e suas divisões, que irão compor um habitus jurídico totalmente inclinado para posturas proféticas que direcionam o papel dos autores e agentes do campo do direito a meros leitores e aplicadores da lei em que, no raro acaso de participarem da criação da lei, tentam dissimulá-la por seus refúgios simbólicos na aparência e na tradição.

\footnotetext{
A legitimidade, que se acha praticamente conferida ao direito e aos agentes jurídicos pela rotina dos usos que dela se fazem, não pode ser compreendida nem como efeito do reconhecimento universalmente concedido pelos «jusriciáveis» a uma jurisdição que, como quer a ideologia profissional do corpo dos juristas, seria o enunciado de valores universais e eternos, portanto, transcendentes aos interesses particulares, nem, pelo contrário, como efeito da adesão inevitavelmente obtida por aquilo que não passaria de um registro do estado dos costumes, das relações de força ou, mais precisamente, dos interesses dos dominantes. (BOURDIEU, 1989, p. 240).
} 
É por isso que, na visão de Bourdieu, ao considerar que a elaboração do direito é oriunda de um movimento de costumes em direção à regra, é preciso se considerar o conjunto das relações objetivas entre o campo jurídico, lugar de relações complexas que obedece a uma lógica relativamente autônoma, e o campo do poder e, por meio dele, o campo social no seu conjunto (BOURDIEU, 1989, p. 241), sendo na intersecção interior desse universo de relações que definem-se os meios, fins e efeitos da ação jurídica, que não deve ser indiferente às reinvidicações e expressões sociais dominadas (subalternas), mas, ao contrário, complexa ao ponto de adequar seu próprio habitus hierarquizado às estruturas sociais compostas que integram o mundo da vida.

\section{Considerações finais.}

Ao elucidar as estruturas de poder voltadas a uma imposição ideológica de poder simbólico, é que, a partir de Bourdieu, pode-se entender que a compreensão clara e ampla sobre a cultura jurídica, como um todo, é uma possibilidade crítica, pois há a possibilidade de se desvelar e desconstruir aquilo que tradicionalmente se instituiu como habitus jurídico. Em outras palavras, só se pode exercer a eficácia específica do direito "na medida em que obtém o reconhecimento, quer dizer, na medida em que permanece desconhecida a parte maior ou menor de arbitrário que está na origem do seu funcionamento (BOURDIEU, 1989, p. 243).

Para Bourdieu, então, o direito, a partir do momento em que há um questionamento entre dominados acerca da violência simbólica dos dominantes, vai se auto-regular com a participação popular, sendo essa "a estrutura do jogo e não um simples efeito de agregação mecânica, que está na origem de transcendência, revelada pelos casos de inversão das instituições, do efeito objectivo e colectivo das acções acumuladas" (BOURDIEU, 1989, p. 254). Através disso, o pensador pondera que o direito faz o mundo social - ou aquilo que Habermas chamará de mundo da vida - mas considerando que ele também é feito por este. Resumidamente, o direito está dentro da análise cultural que Bourdieu faz das estruturas estruturantes, que nada mais é que um estruturalismo crítico.

Habermas concorda com Bourdieu ao afirmar que o direito faz a sociedade e, concomitantemente, também é feito por ela. Isso porque possui a função de medium entre sistemas e mundo da vida, atrelando uma relação de reciprocidade fundamentada na racionalidade comunicativa. Para Habermas, isso funciona (ou deveria funcionar) com um uso 
público da liberdade comunicativa, fazendo com que o princípio do discurso assuma uma figura de princípio da democracia por meio do medium do direito, onde ambos se entrelaçam, constituindo um sistema de direitos no qual autonomia privada e pública se pressupõem de modo recíproco, fazendo com que toda Constituição seja um projeto que só pode ter duração no modo de uma interpretação constitucional contínua, o que faz com que os direitos fundamentais políticos tenham de institucionalizar o uso público das liberdades comunicativas na forma de direitos subjetivos, e assim, ao construir um contexto jurídico através do discurso dos cidadãos dotados de autonomia, a juridificação da liberdade comunicativa passa a significar que o direito precisa se abrir para fontes de legitimação das quais não pode dispor (HABERMAS, 2020, p. 178-181), desencadeando um contexto democrático, onde a cultura jurídica seja fundamentada pela própria autonomia (discursiva e comunicativa) e autodeterminação dos sujeitos sociais dotados de cidadania, que internalizam o contexto moral e constituem, junto dos aparatos juridificados, uma cultura jurídica vinculada à ação comunicativa da sociedade.

Raymond Williams, mesmo que omisso na questão do direito - objetivamente, ao menos - não deixa de dar respaldo e complementariedade teórica a Habermas e Bourdieu, principalmente ao entender que as expressões culturais são condicionadas e, ao mesmo tempo, condicionam a cultura (aqui podendo se ler cultura jurídica). Através do estudo do materialismo-histórico dialético, Williams consegue elucidar claramente a ideia de cultura de forma que se compreendam as estruturas de dominação através das expressões culturais, das manifestações estéticas e a consolidação das hegemonias através da dominação das tradições. Williams ainda teoriza o desenvolvimento antropológico e intrínseco à cultura que os processos históricos desencadeiam, onde a compreensão desses processos e, consequentemente, das consequências da dominação atrelada a esses processos, desencadeia as estruturas de sentimento que permitem o questionamento das hegemonias preponderantes.

Sendo assim, o direito é um processo histórico e é um processo linguístico, a linguagem jurídica expressa uma relação de poder, sendo ela simbólica ou material conforme aludido anteriormente sobre o alinhamento entre Williams e Bourdieu na compreensão de simbólico e material. Compreender isso criticamente permite desvelar figuras de dominação. Esse reconhecimento desmascara a ilusão moderna da linguagem neutra que se atrela ao direito, uma vez que todas as palavras possuem cargas de informações intrínsecas a 
elas e os significados culturalmente atribuídos à sociedade consolidam as estruturas hegemônicas de dominação.

Faz-se necessário, porém, esclarecer que o presente trabalho se trata de uma análise preliminar tanto dos autores quanto do termo cultura, fazendo com que tudo o que foi pesquisado possua uma contribuição até certo nível que foi demonstrado em suas respectivas partes do texto, zelando pelo alinhamento teórico das obras com o objeto de estudo. Em outras palavras, por mais que certos autores aqui estudados possuam teorias pontualmente divergentes, o presente estudo possui a pretensão de demonstrar de forma concisa e clara as contribuições de consenso universal que compõem conceitos nucleares e imprescindíveis alinhados com o propósito dos autores do trabalho.

\section{Referências.}

BOURDIEU, Pierre. A Distinção: crítica social do julgamento. Trad. Daniela Kern, Guilherme J. F. Teixeira. 2 ed. Porto Alegre: Zouk, 2011.

. A dominação masculina. 3 ed. Rio de Janeiro: Bertrand Brasil, 2003.

Sobre a televisão. Rio de Janeiro: Jorge Zahar, 1997.

Sobre o Estado: Curso no Collège de France (1989-1992). São

Paulo:Companhia das Letras, 2014.

O poder simbólico. Lisboa: Difel difusão editorial, 1989.

EAGLETON, Terry. A ideia de cultura. Lisboa: Actividades Editoriais, 2003.

HABERMAS, Jürgen. Facticidade e validade: contribuições para uma teoria discursiva do direito e da democracia. Trad. Felipe Gonçalves Silva, Rúrion Melo. Vol. 1. São Paulo: Editora Unesp, 2020.

PASSIANI, Enio. Afinidades seletivas: uma comparação entre as sociologias da literatura de Pierre Bourdieu e Raymond Williams. Estudos de Sociologia, Araraquara, v.14, n.27, p.285299, 2009.

TINEU, Rogério. Ensaio sobre a teoria das classes sociais em Marx, Weber e Bourdieu. Aurora: revista de arte, mídia e política, São Paulo, v.10, n.29, p. 89-107, jun.-set.2017.

WILLIAMS, Raymond. Marxismo e Literatura. Rio de Janeiro: ZAHAR, 1979. 
Palavras-chave: um vocabulário de cultura e sociedade. Tradução de Sandra Guardini Vasconselos. São Paulo: Boitempo, 2007.

. Cultura. São Paulo: Paz e Terra, 2011a.

Unesp, 2011b.

Cultura e materialismo. Tradução de André Glaser. São Paulo: Editora 